\title{
Peer Mentorship Program in Dental Education
}

\author{
Tien Ha-Ngoc ${ }^{1} \&$ Sang E. Park ${ }^{2, *}$ \\ ${ }^{1}$ University of Illinois at Chicago, College of Dentistry, Chicago, IL, USA \\ ${ }^{2}$ Harvard School of Dental Medicine, Boston, MA, USA \\ *Correspondence: Harvard School of Dental Medicine, 188 Longwood Avenue, Boston, MA 02115, USA. Tel: \\ 1-617-432-4247. E-mail: sang_park@hsdm.harvard.edu
}

Received: January 26, 2015

Accepted: November 9, 2015

Online Published: November 15, 2015

doi:10.5430/jct.v4n2p104

URL: http://dx.doi.org/10.5430/jct.v4n2p104

\begin{abstract}
The Senior Mentorship Program (SMP) was created to encourage the fourth year dental students to act as mentors in the clinical environment as well as facilitate learning of clinic protocols and reinforce concepts in treatment planning for the third year students. Third year dental students engaged in educational conversations and received helpful advice as they entered their clinical years. Fourth year students also benefited from the program by learning how to mentor and teach in an interactive learning environment. Teaching and mentoring can also help fourth year students learn the material more in depth as student teachers, while providing emotional and social support for their peer learners. Third year students reported overwhelmingly positive experiences in the student satisfaction surveys. The majority of students sought mentorship from the peer teachers in areas of Prosthodontics and Treatment Planning, followed by technical instructions on using the Electronic Health Records. The SMP appeared to be an effective educational model to encourage peer-to-peer interaction and enhance learning in a critical period of clinical education.
\end{abstract}

Keywords: peer teaching; mentoring; health care education; dental education

\section{Introduction}

A strong emphasis on treatment planning is placed in the third and fourth year clinical curriculum as dental students are exposed to patient care at Harvard School of Dental Medicine (HSDM). In particular, students are responsible for treatment planning and exhibiting thoroughness and understanding in documenting and presenting cases on both clinical and radiographic findings, which are approved by faculty. The third year marks the first time students provide care for their own patients, as opposed to assisting faculty members or fourth-year students. As a result, the Senior Mentorship Program (SMP) was created to encourage the fourth-year students to act as mentors in the clinical environment as well as facilitate learning of clinic protocols and reinforce concepts in treatment planning for the third-year students.

Peer-to-peer teaching has been linked to enhanced learning and to suggestions that academically weaker students may benefit from this unique teaching methodology. (Park, Kim \& Anderson 2014; Nieder, Parmelee, Stolfi, \& Hudes, 2005) It is speculated that peer influence exhibited through peer teaching by group members and through social pressure could assist the weaker student in understanding course materials. (Michaelsen \& Black, 1994) Peer teaching offers an opportunity for students to learn the material while finding guidance through emotional support and mentorship from upper classmen. The experience has beneficial influence on the peer teachers as they learn the material more in depth while learning how to teach, and peer teachers may also develop interest in pursuing academic careers. (Hum, Maccaro, \& Park, 2014)

The more experienced fourth year students with more exposure to clinical dentistry served as student mentors for third year students who were relatively new to the clinic. The SMP was effective in encouraging peer-assisted learning and peer teaching that promoted a collaborative, self-directed and active learning environment among students at similar or differing levels of education. (Clarke \& Feltham, 1990; Walker-Bartnick, Berger, \& Kappelman, 1984) This learning model also encourages students to learn from each other through increased peer-to-peer interactions and team learning in a collaborative learning environment. (Illeris, 2003; McDonald, 2012) Peer tutoring provides an environment for the tutee to learn the material while finding guidance through emotional 
support and mentorship from peers. Studies on cross-year peer tutoring programs in healthcare have mostly involved junior students being tutored by senior students on physical exam and clinical skills topics in addition to general academic assistance programs. (Hum et al., 2014) Evidence suggests that peer tutoring has many positive effects for the tutees, including improved test scores, student satisfaction, personal and professional development. (Topping, 1996)

The purpose of this study was to describe the Senior Mentorship Program that was implemented to encourage a peer-to-peer learning environment for third and fourth year students in their clinical education.

\section{Materials and Methods}

Fourth-year students acting as senior mentors held 16 weekly sessions between August and December of 2013. Senior mentors who were in the fourth year of their dental education were available for the third-year students to ask questions in the areas of treatment planning, clinical procedures, and pre-clinical processes, as well as general advice and support. The sessions were adaptable to both group learning and one-on-one mentorship, depending on the topics discussed. At each session, mentors kept a log of what topics were covered as well as a record of attendance. During the 16-week period, 20 third-year students participated, and 8 fourth-year students were available as mentors, involving about $40 \%$ of both classes combined. Fourteen of the twenty third-year students completed a survey regarding their experience during SMP (Table 1), and the data were used to evaluate program effectiveness and areas of improvement. The study was reviewed by the Institutional Review Board at Harvard Medical School and Harvard School of Dental Medicine.

Table 1. Survey Given to Participating Third Year Students

Did the program provide you the help you were seeking?

Were the objectives of the program clearly stated?

What skills did you improve upon over the course of the program?

\section{How would you rate the overall program experience?}

How engaged was the student teacher?

\author{
How would you rate the student teacher's knowledge of \\ dentistry?
}

How would you rate the student teacher's teaching skills?

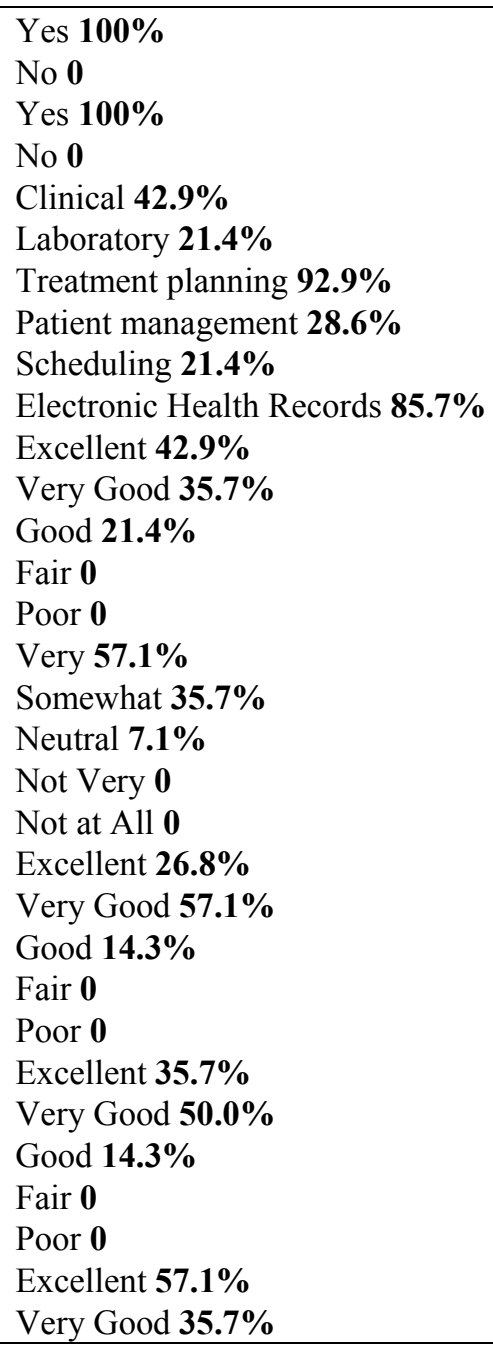




\begin{tabular}{ll}
\hline & Good $\mathbf{7 . 1 \%}$ \\
& Fair $\mathbf{0}$ \\
Would you like to work with a student teacher again? & Poor $\mathbf{0}$ \\
& Yes $\mathbf{1 0 0 \%}$ \\
& No $\mathbf{0}$ \\
I more readily asked student teachers certain questions & Strongly Agree $\mathbf{4 2 . 9 \%}$ \\
rather than faculty. & Agree $\mathbf{5 0 . 0 \%}$ \\
& Neutral $\mathbf{7 . 1 \%}$ \\
& Disagree $\mathbf{0}$ \\
Would you consider being involved in SMP as a student & Strongly Disagree $\mathbf{0}$ \\
teacher? & Yes $\mathbf{8 5 . 7 \%}$ \\
\hline
\end{tabular}

\section{Results}

Over half of the participating third-year students sought frequent guidance on prosthodontic procedures or on treatment planning (Figure 1). Endodontic procedures were the third most frequently discussed topic, with $11 \%$ of the total. When asked what skills they had improved over the course of the program, $92.9 \%$ of students reported improvement in treatment planning, 85.7\% reported improvement in use of Electronic Health Records, and 42.9\% reported improvement in clinical skills (Table 1). The student satisfaction survey showed that $100 \%$ of students felt that the program had provided them the help they were seeking. $42.9 \%$ of students rated the overall experience of the program as excellent and $57.1 \%$ of students rated the overall assessment of the student teachers' performance as excellent. In addition, $85.7 \%$ of students reported that they would like to be involved in SMP as a student teacher the following year and $100 \%$ of students stated that they would like to work with a student teacher again. Students reported that they would approach a student teacher rather than faculty for certain topics because of the student teacher's approachability (Figure 2). Student teacher availability was also rated highly as a reason for asking student teachers certain questions. Comments from third year students were encouraging, with many expressing gratitude for the peer tutor's time and effort and wanting to keep a consistent program that was sustainable for future classes.

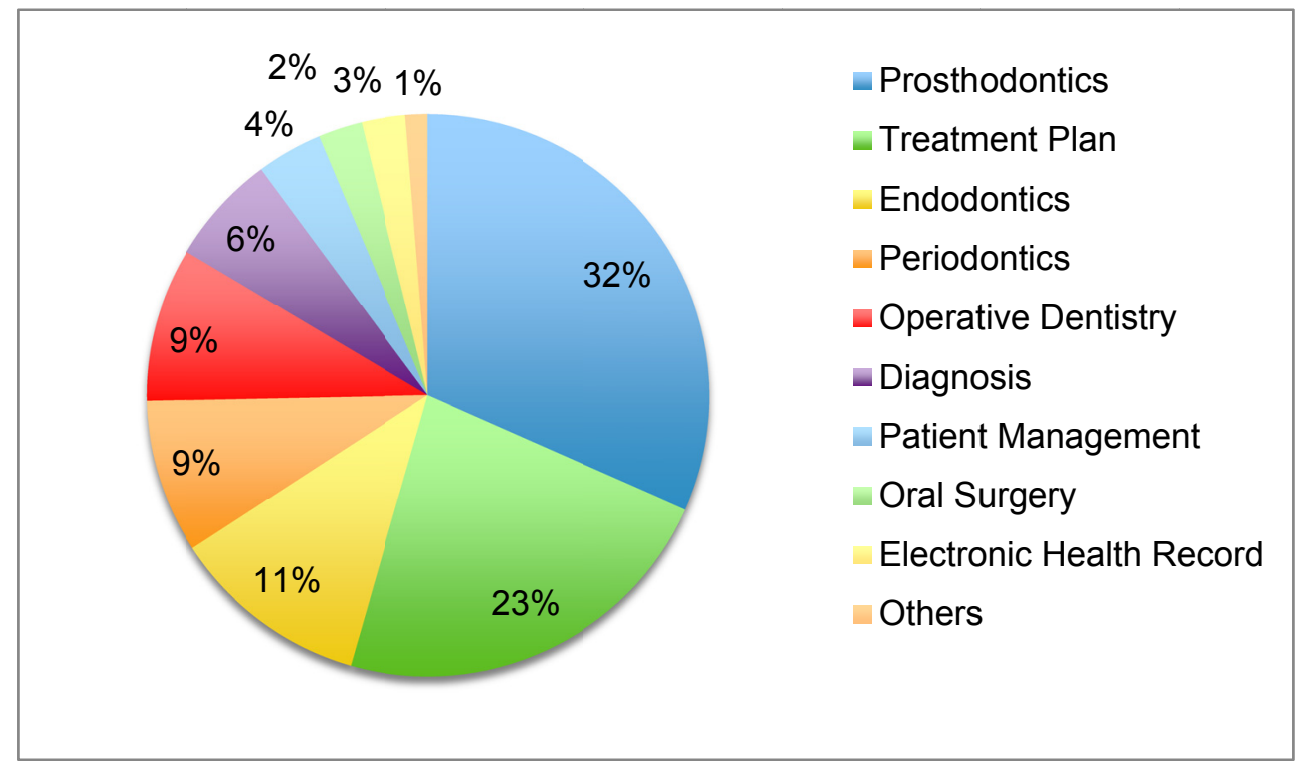

Figure 1. Frequency of Topics Discussed 


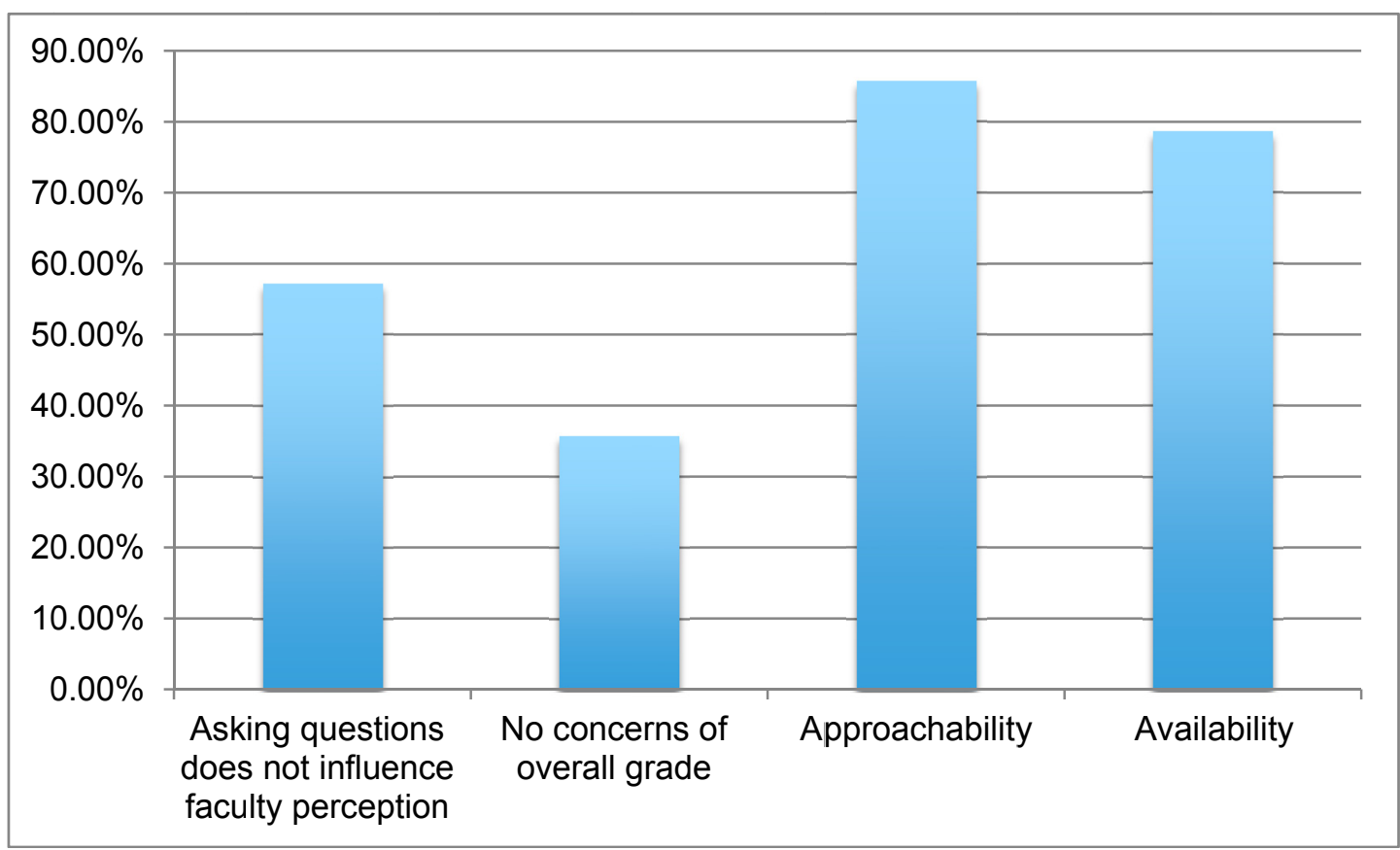

Figure 2. Reasons for Asking Student Teachers Certain Questions

Reported advantages of the overall SMP by students included: "Invaluable help with treatment planning from those who recently were in our shoes!", "I was able to ask questions without being afraid of sounding incompetent", "Easy access to knowledgeable and friendly classmates", and "Student mentors understand other students' problem better and know where the questions/problems are coming from." Students commented on disadvantages of the SMP as being "Limited availability/number of fourth years helping" and "Early in the year the program was a bit crowded. This seemed to taper down with time."

Student-reported advantages of student teaching included: "They're closer to being on our level and are non-judgmental; have good advice about patient management and about navigating HSDM as students.", "Direct and useful practical knowledge beyond the core teaching points" and "Understand pertinent issues that come up in the teaching practice". Reported disadvantages of student teaching included "Limited treatment planning and clinical experience of the student teachers" and "Potential for incorrect information".

\section{Discussion}

Peer teaching reflects interactions with others who are not professional teachers, but help each other to learn and learn themselves from teaching. (Topping, 1996) With this expected combination of outcomes, the SMP was examined to determine the effectiveness in maintaining the academic performance of students while enhancing their education. A 2011 study found that in the 36 dental schools responding to the survey, 25 of the programs implement some formal teaching program involving teaching assistants, fellowships, or peer tutoring. The SMP and similar programs could benefit student mentors by preparing them to teach at some point in their careers, and could also have the potential to initiate interest in the pursuit of academic careers.

With greater financial demands and a need to generate new dentists with plans to enter academic careers, programs that encourage students to teach are vital to dental education institutions and the field as a whole. Our previous study did a critical review of the literature involving cross-year peer tutoring programs that involved the pairing of junior and senior students to elucidate characteristics necessary for future studies on peer teaching programs. (Hum et al., 2014) It was determined that the dental field is in great need of studies in dental education that cover preclinical education, and that additional focus of future studies should be placed on qualitative outcomes for tutors and their interests in teaching careers. Currently dental education institutions are often faced with shortages of available full-time faculty, as a result of a small number of graduates with immediate plans to enter teaching. It is important to the dental field that educational institutions prioritize the development and training of future educators. Therefore, opportunities for students to teach during dental school could potentially increase the likelihood that these peer teachers would pursue teaching in their careers as a result of their experience. 
It was observed that third year students are not only feeling more comfortable asking for help but are also asking more in-depth questions about treatment planning, due to their increasing experience with patients and other clinical and pre-clinical procedures. We have received very encouraging feedback from these students. Additionally, the senior students reported that they have more clinical knowledge about dentistry than they realized and were able to make contributions to the experience.

The third-year students had taken a course in diagnosis and treatment planning before the mentorship period, and took a three-month course in prosthodontic treatment during the mentorship period (September to December), which explains a high volume of interest and guidance on prosthodontics necessary in the program.

Preclinical education in dentistry is focused on learning procedural skills for healthcare delivery to patients. Therefore, the dental field is in need of high-powered studies on peer tutoring programs centered on preclinical education. Additionally, the field requires more high powered studies involving peer tutoring programs that focus on multiple topics and skills rather than programs teaching very specific skill sets, which causes concern that the success of those programs may not be generalizable to peer tutoring for other topics. (Goodfellow \& Schofield, 2001; Weyrich et al., 2009; Perkins, Hulme, \& Bion, 2002; Tolsgaard et al., 2007)

It has been reported that $69 \%$ of surveyed dental education institutions already utilize formal student teaching programs, in order to stimulate interest in academic careers. (McAndrew, Brunson, \& Kamboj, 2011) In terms of positive benefits for tutors, these tutors may pursue teaching in their careers as a result of their experience. This aspect of the program could play a vital role for dental education institutions because of the high demand for dental faculty. This makes further research on the qualitative outcomes of peer tutoring programs important to the dental profession as a whole.

Studies in other health sciences have shown that team-based learning (TBL), which reflects peer-to-peer teaching, can be an effective teaching method. In a study to investigate how easily and accurately dental students were able to identify carious lesions using radiographs, and to determine whether caries detection and activity assessment were facilitated by team-based learning methods, results showed that the team-based learning methods facilitated correct assessment of caries detection and activity to a degree. (Park et al., 2014) It was demonstrated that the teams performed better in correct evaluation of learning foundational clinical training, compared to the individual students. Peer-assisted learning or peer teaching and learning could be an effective educational method that promotes a collaborative learning environment among peers.

The peer-to-peer learning environment naturally fosters mentorship and small group learning. This seems to be particularly true in the dental school setting, especially with a small student body at HSDM. Informal discussions already allow for transfer of useful tips between third and fourth year students at HSDM. The creation of the SMP allowed for a structured environment for teaching and mentorship.

Peer teachers may not be content experts and lack the understanding of the associated curriculum; however, in a problem-based curriculum (PBL), studies have found no statistically significant difference in performance of students taught by experts or non-experts of the subject in PBL tutorials. (Park, Susarla, Cox, Da Silva, \& Howell, 2007) This was attributed to the fact that the role of a tutor in PBL is to facilitate rather than to deliver knowledge. In addition, peer mentoring provided students with an opportunity to ask questions of their peers which they might have hesitated to ask of faculty members. Peer teachers in the mentorship program, despite not having expertise in the subject, might be capable of supplementing faculty roles.

Despite the promising results of the SMP survey, further studies on the peer mentorship program in the context of the overall curriculum must be done to determine its effectiveness. Some students who are excellent clinicians may need more guidance teaching, and it is important, especially in a peer mentorship situation, that a student seeking help should not be given confusing or incorrect information. Also, additional studies on these programs are necessary to report more in-depth descriptions of the surrounding curriculum in order for their results to be applicable in curriculum design processes. Future directions for study include assessment of treatment plan summative grades for those students who participated versus those who did not to see if there is a statistically significant difference. It would be useful in the future to obtain a measure of peer teachers, as it is also important to note that such sessions would benefit the students by providing them with an additional opportunity for them to increase their own clinical learning.

These programs, while helping students to learn, may also encourage peer teachers to include academic teaching as part of their future career plans. The shortage of full-time dental faculty forces dental institutions to supplement faculty teaching with other pedagogical methods, among which peer mentoring has promise as both an effective 
method of information delivery to students and a potential conduit for development of future dental educators.

\section{Conclusion}

The SMP allowed for a structured environment for peer-to-peer teaching and mentorship that has the potential to facilitate student learning. With more contributions to this method of learning in the dental field that specifically target clinical dental education, dental institutions can incorporate more interactive student-led mentorship programs into their curricula.

\section{References}

Clarke B., \& Feltham W. (1990). Facilitating peer group teaching within nurse education. Nurse Education Today, 10, 54-57. http://dx.doi.org/10.1016/0260-6917(90)90139-H

Goodfellow PB., \& Schofield E. (2001). Peer tutorials amongst medical students. Medical Education, 35(10), 1001-1002. http://dx.doi.org/10.1111/j.1365-2923.2001.1048d.x

Hum L., Maccaro J., \& Park SE. (2014). Cross-year peer tutoring in health care education: A review of the literature. Journal of Curriculum and Teaching, 3(2), 43-57. http://dx.doi.org/10.5430/jct.v3n2p43

Illeris K. (2003). Three Dimensions of Learning: Contemporary learning theory in the tension field between the cognitive, the emotional and the social. Malabar, Florida: Krieger.

McAndrew M., Brunson WD., \& Kamboj K. (2011). A survey of U.S. dental school programs that help students consider academic careers. Journal of Dental Education, 75(11), 1458-1464.

McDonald PL. (2012). Adult learners and blended learning: a phenomenographic study of variation in adult learners' experiences of blended learning in higher education [dissertation]. Washington, DC, George Washington University.

Michaelsen LK., \& Black RH. (1994). Building learning teams: The key to harnessing the power of small groups in higher education. In: Kadel S, Keener J, (eds.), Collaborative Learning: A Sourcebook for Higher Education. Vol 2. State College: National Center for Teaching, Learning, and Assessment, 65-81

Nieder GL., Parmelee DX., Stolfi A., \& Hudes PD. (2005). Team-based learning in a medical gross anatomy and embryology course. Clinical Anatomy, 18, 56-63. http://dx.doi.org/10.1002/ca.20040

Park SE., Kim A., \& Anderson N. (2014). Evaluating a team-based learning method for detecting dental caries in dental students. Journal of Curriculum and Teaching, 3(2), 100-105. http://dx.doi.org/10.5430/jct.v3n2p100

Park SE., Susarla SM., Cox CK., Da Silva J., \& Howell TH. (2007). Do tutor expertise and experience influence student performance in a problem-based curriculum? Journal of Dental Education, 71(6), 819-824. http://dx.doi.org/10.1007/s00134-002-1291-9

Perkins GD., Hulme J., \& Bion JF. (2002). Peer-led resuscitation training for healthcare students: a randomised controlled study. Intensive Care Medicine, 28(6), 698-700.

Tolsgaard MG., Gustafsson A., Rasmussen MB., Høiby P., Müller CG., \& Ringsted C. (2007). Student teachers can be as good as associate professors in teaching clinical skills. Medical Teacher, 29(6), 553-557. http://dx.doi.org/10.1080/01421590701682550

Topping KJ. (1996). The effectiveness of peer tutoring in further and higher education: a typology and review of literature. Higher Education, 32, 321-345. http://dx.doi.org/10.1007/BF00138870

Walker-Bartnick L., Berger J., \& Kappelman M. (1984). A model for peer tutoring in the medical school setting. Journal of Medical Education, 59, 309-315. http://dx.doi.org/10.1097/00001888-198404000-00004

Weyrich P., Celebi N., Schrauth M., Möltner A., Lammerding-Köppel M., \& Nikendei C. (2009). Peer-assisted versus faculty staff-led skills laboratory training: a randomised controlled trial. Medical Education, 43(2), 113-120. http://dx.doi.org/10.1111/j.1365-2923.2008.03252.x 